\title{
Article \\ Reliability Assessment of Space Station Based on Multi-Layer and Multi-Type Risks
}

\author{
Xiaopeng $\mathrm{Li}^{1,2, *}$ and Fuqiu $\mathrm{Li}^{2}$ \\ 1 School of Mechanical and Electrical Engineering, University of Electronic Science and Technology of China, \\ Chengdu 611731, China \\ 2 China Astronautics Standards Institute, Beijing 100071, China; lifuqiu2004@126.com \\ * Correspondence: lixp@spacechina.com; Tel.: +86-10-8810-8253
}

Citation: Li, X.; Li, F. Reliability Assessment of Space Station Based on Multi-Layer and Multi-Type Risks. Appl. Sci. 2021, 11, 10258. https://doi.org/10.3390/ app112110258

\section{Academic Editors:}

Hongzhong Huang, Yanfeng Li and $\mathrm{He} \mathrm{Li}$

Received: 17 August 2021

Accepted: 8 October 2021

Published: 1 November 2021

Publisher's Note: MDPI stays neutral with regard to jurisdictional claims in published maps and institutional affiliations.

Copyright: (c) 2021 by the authors. Licensee MDPI, Basel, Switzerland. This article is an open access article distributed under the terms and conditions of the Creative Commons Attribution (CC BY) license (https:// creativecommons.org/licenses/by/ $4.0 /)$.

\begin{abstract}
A space station is a typical phased-mission system, and assessing its reliability during its configuration is an important engineering action. Traditional methods usually require extensive data to carry out a layered reliability assessment from components to the system. These methods suffer from lack of sufficient test data, and the assessment process becomes very difficult, especially in the early stage of the configuration. This paper proposes a reliability assessment method for the space station configuration mission, using multi-layer and multi-type risks. Firstly, the risk layer and the risk type for the space station configuration are defined and identified. Then, the key configuration risks are identified comprehensively, considering their occurrence likelihood and consequence severity. High load risks are identified through risk propagation feature analysis. Finally, the configuration reliability model is built and the state probabilities are computed, based on the probabilistic risk propagation assessment (PRPA) method using the assessment probability data. Two issues are addressed in this paper: (1) how to build the configuration reliability model with three layers and four types of risks in the early stage of the configuration; (2) how to quantitatively assess the configuration mission reliability using data from the existing operational database and data describing the propagation features. The proposed method could be a useful tool for the complex aerospace system reliability assessment in the early stage.
\end{abstract}

Keywords: reliability assessment; risk propagation; PRPA; multi-layer risks; multi-type risks; space station

\section{Introduction}

The space station is one of the most complex aerospace phased-mission systems, with a structure that includes several associated modules and a configuration process involving dozens of manned flight and cargo flight missions [1-3]. Due to the structure's dynamic changes, reliability assessment is the main technical means to judge configuration effectiveness [4]. In complex system reliability fields, the Bayesian approach [5], Semi-Markov process [6], Monte Carlo simulation [7], Markov regenerative process [8], probabilistic safety assessment (PSA) [9], probability risk assessment (PRA) [10], dynamic probabilistic risk assessment (DPRA) [11], integrated probabilistic risk assessment (IPRA) [12], engineering risk assessment [13], occupational risk assessment [14], operational risk assessment [15], uncertainty and decision making [16,17], and common cause failures [18-22] have been widely used. However, it is difficult to model and assess space station configuration reliability in the early stage using the above-mentioned methods because of two problems. One is the refined model problem. The space station configuration reliability is influenced by the platform equipment, the space environment, and the astronauts. It is difficult to build a reliability model including the above three factors and covering components, subsystem, and system layers. The other problem is the large amount of data needed. During the configuration process, especially in the early stage, the platform equipment tests are still going on, and the available data for the assessment is very limited. Risk identification 
and management is a very important task throughout the whole configuration process. The risks identified can describe the configuration states, and the relationships between different layers and types can represent the static and dynamic risk features. Probability data on partial risks incurred in other aerospace projects are collected in the existing operational database. So, in the early stage of the configuration, the risks can be used to assess the configuration reliability. According to the above analysis, this paper proposes a PRPA method. It combines the PRA method and risk propagation theory $[23,24]$ to solve the reliability assessment problems.

The structure of this paper is organized as follows. In Section 2, the framework of the space station configuration reliability assessment is given. Then, according to the classification and stratification criteria, multi-layer and multi-type risks are identified in Section 3. Section 4 analyzes the occurrence, consequence, and propagation features of the multi-layer and multi-type risks based on the risk qualitative evaluation matrix and the Leader Rank algorithm [25-27]. The model of the space station configuration reliability is built in Section 5, and the risk data is collected in Section 6. Section 7 uses the tool QRAS [28] to quantitatively assess the space station configuration reliability based on the PRPA method. The conclusions and future works are given in Section 8.

\section{Framework of Space Station Configuration Reliability Assessment}

According to the above analysis, the framework of the space station configuration reliability assessment is determined and shown in Figure 1. The framework can be divided into five steps: risk definition and identification, risk features analysis, reliability modeling, risk data collection, and reliability assessment. The details are shown as follows.

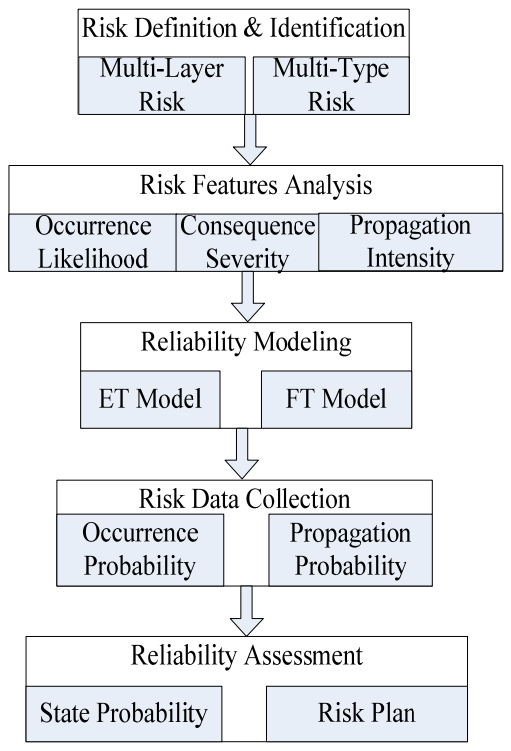

Figure 1. Framework of the space station configuration reliability assessment.

(1) Risk definition and identification

The space station configuration risks consist of multi-layer and multi-type risks in the flight missions, and risk definition and identification are the beginning of the other steps. This step determines the domain of the space station configuration reliability modeling and assessment work.

(2) Risk features analysis

Traditional risk feature analysis mainly focuses on occurrence and consequence features, but the propagation feature is the most important issue of the space station configuration risk. This paper adopts qualitative and quantitative methods to analyze the risk features. This step identifies the key risks in all of the space station configuration risks. 
(3) Reliability modeling

In the reliability modeling step, the traditional PRA method including the Event Tree (ET) $[29,30]$ and the Fault Tree (FT) [31,32] methods are improved by incorporating complex network theory [33-36] to describe the risk propagation features. Based on the risk definition, identification and features analysis, the configuration reliability model can be built using the PRPA method.

(4) Risk data collection

After the risk features analysis, the risk data collection has been determined, and the static and dynamic features data are necessary. The static features data comes from the existing operational database, and the dynamic features data comes from the propagation feature analysis results.

(5) Reliability assessment

All the model building and data collection works are the basis of reliability assessment. Then, the reliability assessment results, which contain the space station configuration mission final state probabilities, can be evaluated in this step. The risk control plan can also be made based on the assessment results.

\section{Risk Definition and Identification of Space Station}

\subsection{Risk Definition}

In the space station configuration mission, there are four final states that need to be researched, they are full success, success, partial success, and failure, respectively. In the engineering area, only the first state is the most expected state, and the other three states are undesirable states. The middle two states have no damages to the platform and the crew, and their risks can be defined as mission risks, which can be described by using the terminology loss of mission (LOM). The last state means that the mission failure may cause damage to the platform or the crew, and it should be studied to find the reasons and adopt countermeasures. The risks of the failure state can be defined as safety risks, and described using the terminologies of loss of crew (LOC) and loss of platform (LOP). Therefore, the space station configuration risks include mission risks and safety risks.

Because of the different compositions and functions implemented by different subsystems (such as the power subsystem, the guidance, navigation, and control subsystems) and different missions (such as manned missions and cargo missions), different layers and different type of risks will affect the space station configuration mission.

According to the influence domain, configuration risks can be divided into three layers: inner-system risks, between-system risks, and between-mission risks. Their definitions are shown as follows.

(1) Inner-system risks

Inner-system risks occur inside one system and affect the system functions. They have the propagation characteristic, and also cause damage to the equipment in the system, but they do not cause damage to the other systems.

(2) Between-system risks

Between-system risks occur at the interfaces between the systems and affect singlemission completion. They can cause damage to the other systems in one single flight mission, but not to the whole configuration mission.

(3) Between-mission risks

Between-mission risks occur between the adjacent missions. They cause damage to the other flight missions and affect the whole configuration mission.

According to engineering experience, there are four main types of risks: technology risks, management risks, product risks, and operation risks. Their definitions are shown as follows.

(1) Technology risks

Technology risks are caused by immature or invalidated key technologies. They will occur at all stages of the configuration mission with a certain degree of concealment. 
(2) Management risks

Management risks are caused by unreasonable work plans, inadequate material guarantees, incorrect risk decisions, and insufficient communication and coordination.

(3) Product risks

Product risks are caused by product failures occurring in the launching and operation stages, and they have the most propagation characteristics.

(4) Operation risks

Operation risks are caused by incorrect operation and handling by the operators in the launch site, flight control center, and on-orbit.

In summary, the space station configuration risks are shown in Figure 2.

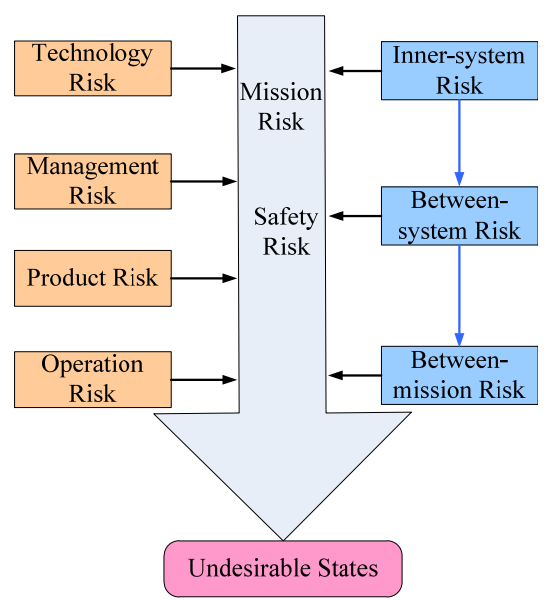

Figure 2. Configuration risks definition of the space station.

\subsection{Risk Identification}

Risk identification often uses preliminary hazard analysis (PHA) $[37,38]$ and system hazard analysis (SHA) [39] methods. For the space station configuration, the multi-layer and multi-type risks identifications use a combination of these methods. According to the PHA and SHA methods, 457 risks are identified and shown in Table 1.

Table 1. Numbers of Multi-layer and Multi-type risks identified.

\begin{tabular}{ccc}
\hline Risk Layer & Risk Type & Risk Number \\
\hline \multirow{2}{*}{ Between-mission risks } & Technology risk & 12 \\
$(57)$ & Management Risk & 5 \\
& Product risk & 23 \\
& Operation risk & 17 \\
Between-system risks & Technology risk & 34 \\
$(166)$ & Management risk & 11 \\
& Product risk & 87 \\
Inner-system risks & Operation risk & 34 \\
$(234)$ & Technology risk & 56 \\
& Management risk & 18 \\
& Product risk & 113 \\
& Operation risk & 47 \\
\hline
\end{tabular}

\section{Risk Features Analysis of Space Station}

In general, risk features analysis only contains occurrence likelihood and consequence severity when using the risk matrix method [40], and propagation characteristic analysis is not required. However, the propagation characteristic becomes the third important feature of the configuration risks because of the serial implementations of the space station configuration and risks' close association. In this section, the occurrence likelihood and consequence severity of risks are analyzed based on the qualitative risk matrix method. 
Then, the propagation characteristic of the risks is analyzed with the quantitative complex network theory.

\subsection{Risk Feature Qualitative Analysis}

The risk feature qualitative analysis is based on the risk qualitative evaluation matrix, which is composed of evaluation criterions of occurrence likelihood and consequence severity. According to the engineering practice, the evaluation criterions can be determined, as shown in Tables 2 and 3. Through the consideration of occurrence likelihood and consequence severity criterions, the evaluation risk matrix can be derived and the corresponding rating criterion can be determined as shown in Figure 4. In Figure 3, the configuration risks can be divided into five levels, and all 457 configuration risks' levels can be determined and shown in Table 4 .

Table 2. Evaluation criterion of occurrence likelihood.

\begin{tabular}{ccc}
\hline Level & Logic & Linguistic Descriptions \\
\hline Level 1 & Rarely & The risk hardly occurs in the whole mission \\
Level 2 & Improbable & The risk cannot occur in the whole mission \\
Level 3 & Moderate & The risk occurs with a certain probability \\
Level 4 & Possible & The risk may occur in the whole mission \\
Level 5 & Probable & The risk likely occurs in the whole mission \\
\hline
\end{tabular}

Table 3. Evaluation criterion of consequence severity.

\begin{tabular}{ccc}
\hline Level & Logic & Linguistic Descriptions \\
\hline Level 1 & Unaffected & no damage to the crew and platform \\
Level 2 & Light & light damage to the crew and platform \\
Level 3 & Moderate & some damage to the crew and platform \\
Level 4 & Severe & severe damage to the crew lives and platform condition \\
Level 5 & Fatal & fatal damage to the crew lives and platform condition \\
\hline
\end{tabular}

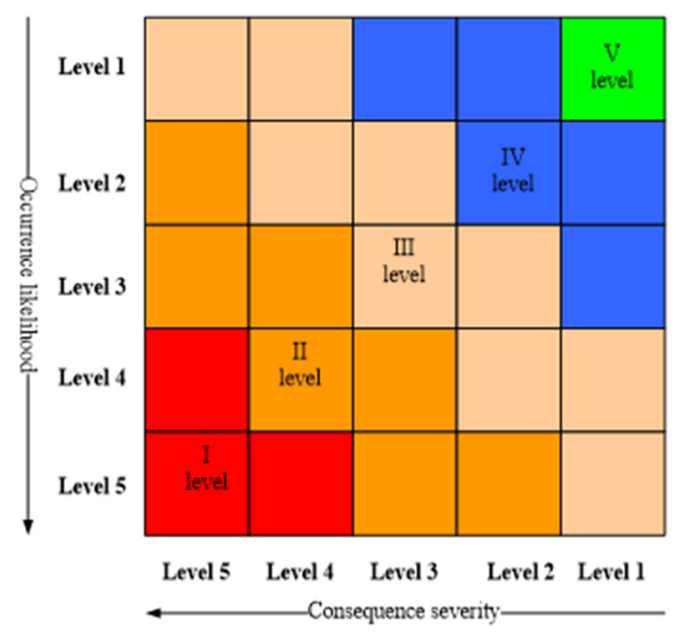

Figure 3. Configuration risks synthetically evaluation matrix. 
Table 4. Multi-layer configuration risks synthetically evaluation results.

\begin{tabular}{cccc}
\hline Risk Level & $\begin{array}{c}\text { Between-Mission } \\
\text { Risk Numbers }\end{array}$ & $\begin{array}{c}\text { Between-System } \\
\text { Risk Numbers }\end{array}$ & $\begin{array}{c}\text { Inner-System } \\
\text { Risk Numbers }\end{array}$ \\
\hline Level V & 19 & 55 & 77 \\
Level IV & 8 & 25 & 46 \\
Level III & 17 & 23 & 26 \\
Level II & 9 & 46 & 54 \\
Level I & 4 & 17 & 31 \\
\hline
\end{tabular}

From Table 4, there are 52 level I risks, and these risks can be regarded as the key risks. Engineering experience shows that the other risks cause limited damage to the configuration mission, and they can be ignored because of their lower risk levels. This can reasonably simplify the configuration reliability model and assessment.

\subsection{Risk Feature Quantitative Analysis}

The configuration risks are related to both the components and structure of the space station. The components represent the static features of the configuration risks, and the structure represents the dynamic features of the configuration risks. The static features can be described by the occurrence probabilities, and the dynamic features can be described by the propagation probabilities. Therefore, the goal of the risk features quantitative analysis is to determine the occurrence and propagation probabilities.

The occurrence probability can be determined by the probability assessment methods [41-43] or by Equation (1)

$$
p_{o i}=n_{i} / n_{\text {total }}, 1 \leq i \leq 52
$$

If the components are treated as the nodes, the complex aerospace system can be regarded as a complex aerospace engineering system network. Research shows that a complex aerospace engineering system network has a larger clustering coefficient and smaller feature path length [44-47], which is consistent with the small-world complex network characteristic. So, the propagation probability can be determined by the smallworld complex network analysis method. Fifty-two key configuration risks are modeled as the nodes to build the network model with UCINET software, and the node eigenvector centrality (EC) $[48,49]$ index can be computed. The EC index describes the node's adjacent nodes and the adjacent nodes' importance, and it can express the node's risk propagation feature. So, the risk propagation probability can be defined by Equation (2).

$$
p_{p i}=E C(i)=\lambda^{-1} \sum_{j=1}^{52} a_{i j} x_{j}, 1 \leq i \leq 52
$$

where $\lambda$ is the maximum eigenvalue of the complex network model adjacency matrix $A, a_{i j}$ is the element in matrix $A$, and $x=\left(x_{1}, x_{2}, \cdots, x_{52}\right)^{\mathrm{T}}$ is the eigenvector corresponding to $\lambda$. Adopting the Leader Rank algorithm to calculate the nodes' risk propagation probabilities, the top 15 highest propagation probability risks can be taken as high load risks and shown in Table 5. Then, the space station configuration reliability model will be built based on the 15 high load risks, and the occurrence probabilities and propagation probabilities of the 15 high load risks will be given in the data collection section. 
Table 5. High load risks of the space station configuration mission.

\begin{tabular}{|c|c|c|c|c|}
\hline No. & Risk Name & Risk Layer & Risk Type & Symbol \\
\hline 1 & $\begin{array}{c}\text { Lack of adequate verification of space } \\
\text { docking technology }\end{array}$ & $\begin{array}{l}\text { Between- } \\
\text { mission }\end{array}$ & Technology & RP11 \\
\hline 2 & $\begin{array}{l}\text { Insufficient verification of large assembly } \\
\text { control technology }\end{array}$ & $\begin{array}{l}\text { Between- } \\
\text { mission }\end{array}$ & Technology & RP12 \\
\hline 3 & $\begin{array}{l}\text { Incomplete coverage of critical } \\
\text { measurement control segment }\end{array}$ & $\begin{array}{l}\text { Between- } \\
\text { system }\end{array}$ & Technology & RP13 \\
\hline 4 & Insufficient continuous launch support & $\begin{array}{l}\text { Between- } \\
\text { system }\end{array}$ & Management & RP14 \\
\hline 5 & Power supply interruption & $\begin{array}{l}\text { Inner- } \\
\text { system }\end{array}$ & Product & RP15 \\
\hline 6 & $\begin{array}{l}\text { Main module failed to enter the } \\
\text { scheduled orbit }\end{array}$ & $\begin{array}{l}\text { Between- } \\
\text { mission }\end{array}$ & Product & $\mathrm{RP} 21$ \\
\hline 7 & Main module out of control & $\begin{array}{l}\text { Between- } \\
\text { mission }\end{array}$ & Product & $\mathrm{RP} 22$ \\
\hline 8 & Rocket thrust deficiency & $\begin{array}{l}\text { Between- } \\
\text { system }\end{array}$ & Product & $\mathrm{RP} 23$ \\
\hline 9 & $\begin{array}{l}\text { Inadequate measurement and control } \\
\text { accuracy }\end{array}$ & $\begin{array}{l}\text { Between- } \\
\text { system }\end{array}$ & Technology & $\mathrm{RP} 24$ \\
\hline 10 & Insufficient on-orbit material support & $\begin{array}{l}\text { Between- } \\
\text { mission }\end{array}$ & Management & RP31 \\
\hline 11 & Main module structure damage & $\begin{array}{l}\text { Between- } \\
\text { system }\end{array}$ & Product & RP32 \\
\hline 12 & $\begin{array}{c}\text { Lack of emergency life-saving training in } \\
\text { the crew }\end{array}$ & $\begin{array}{l}\text { Between- } \\
\text { system }\end{array}$ & Operation & RP33 \\
\hline 13 & Cargo mission failed & $\begin{array}{l}\text { Between- } \\
\text { system }\end{array}$ & Management & RP34 \\
\hline 14 & Cargo ship failure & $\begin{array}{l}\text { Between- } \\
\text { system }\end{array}$ & Product & RP35 \\
\hline 15 & $\begin{array}{l}\text { Main module docking interface } \\
\text { damaged }\end{array}$ & $\begin{array}{l}\text { Inner- } \\
\text { system }\end{array}$ & Product & RP36 \\
\hline
\end{tabular}

\section{Reliability Model of Space Station Configuration}

The space station configuration mission profile can be divided into three phases: key technology verification (KTV), main module launch (MML), and assembly construction $(\mathrm{AC})$, respectively. The configuration mission can be divided into four final states: mission success (MS), LOM, LOC, and LOP. The whole mission is functioning only if all the submissions in different phases are functioning. The KTV, MML, and AC phases failure will lead to LOM, LOP, and the worst final state, LOC, respectively.

The configuration reliability model can be built using QRAS, as shown in Figures 4-7. Figure 4 is the event model, which includes the initial event mission beginning, the pivotal events KTV, MML, and AC. It has four final states as mentioned above. Figures 5-7 are the fault tree models. Figure 5 represents the failure of the KTV phase, which includes five high load risks (RP11, RP12, RP13, RP14, and RP15). Figure 6 represents the failure of the MML phase, and includes four high load risks (RP21, RP22, RP23, and RP24). Figure 7 represents the failure of the AC phase, and includes six high load risks (RP31, RP32, RP33, RP34, RP35, and RP36). All the high load risks are connected to each pivotal event through logic gates because of their high propagation probabilities. 


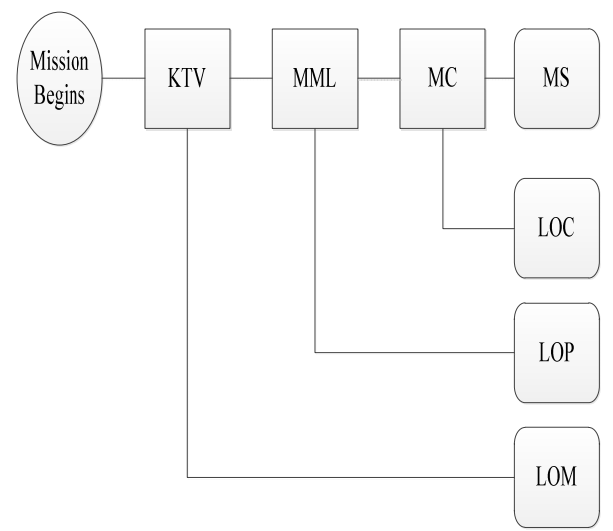

Figure 4. Configuration reliability event tree model.

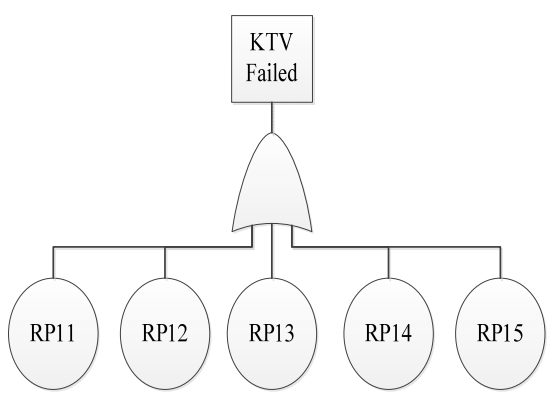

Figure 5. Configuration reliability fault tree model of the KTV phase.

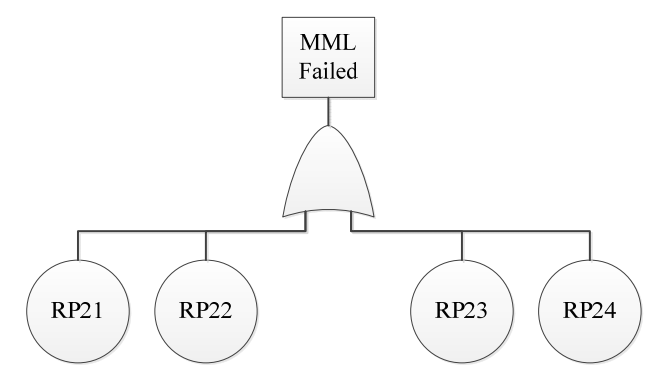

Figure 6. Configuration reliability fault tree model of the MML phase.

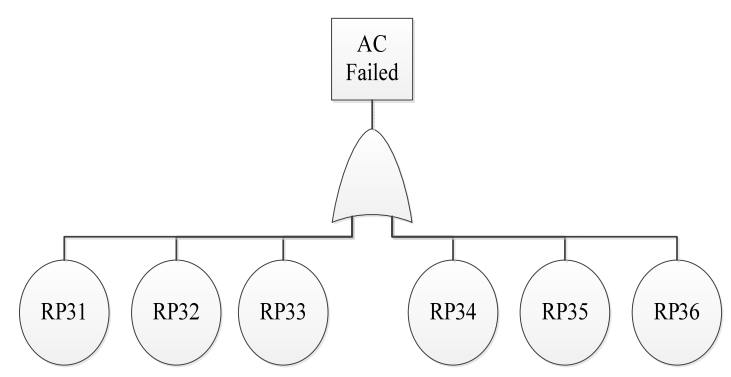

Figure 7. Configuration reliability fault tree model of the AC phase.

The model of the configuration mission reliability is the basis of the reliability assessment. The data of the reliability assessment will be collected.

\section{Data Collection of Space Station Configuration Risks}

Configuration risks data includes the occurrence probabilities and propagation probabilities. For the reliability assessment, the occurrence probabilities and propagation 
probabilities should be used synthetically. Generally, $p_{o i} \leq 10^{-6}, p_{p i} \leq 10^{-8}$, and $p_{o i} \geq p_{p i}$. The assessment probability of the $i$ th high load risk $p_{a i}$ can be defined by Equation (3)

$$
p_{a i}=\sqrt{p_{o i} p_{p i}}, 1 \geq i \geq 15
$$

where $P_{o i}$ is the $i$ th high load risk's occurrence probability, $P_{p i}$ is the high load risk's propagation probability, and $p_{a i}$ is the $i$ th high load risk's assessment probability. Because $p_{p i} \leq p_{a i} \leq p_{o i}$, so $p_{a i}$ can better describe the risk feature. The value of $p_{a i}$. is shown in Table 6.

Table 6. High load risks probabilities of the space station configuration mission.

\begin{tabular}{ccccc}
\hline No. & Risk Symbol & $\boldsymbol{P}_{\boldsymbol{o i}}$ & $\boldsymbol{P}_{\boldsymbol{p i}}$ & $\boldsymbol{P}_{\boldsymbol{a} \boldsymbol{i}}$ \\
\hline 1 & $\mathrm{RP11}$ & $6.4051 \times 10^{-3}$ & $3.8054 \times 10^{-3}$ & $4.937 \times 10^{-3}$ \\
2 & $\mathrm{RP12}$ & $1.4046 \times 10^{-3}$ & $2.1985 \times 10^{-4}$ & $5.557 \times 10^{-4}$ \\
3 & $\mathrm{RP13}$ & $1.2188 \times 10^{-3}$ & $4.6507 \times 10^{-4}$ & $7.529 \times 10^{-4}$ \\
4 & $\mathrm{RP14}$ & $4.156 \times 10^{-3}$ & $9.421 \times 10^{-5}$ & $6.258 \times 10^{-4}$ \\
5 & $\mathrm{RP15}$ & $5.5806 \times 10^{-3}$ & $8.871 \times 10^{-5}$ & $7.036 \times 10^{-4}$ \\
6 & $\mathrm{RP21}$ & $5.9727 \times 10^{-4}$ & $7.2391 \times 10^{-5}$ & $6.575 \times 10^{-4}$ \\
7 & $\mathrm{RP22}$ & $6.7152 \times 10^{-5}$ & $5.4309 \times 10^{-5}$ & $6.039 \times 10^{-5}$ \\
8 & $\mathrm{RP23}$ & $7.82 \times 10^{-5}$ & $3.9489 \times 10^{-5}$ & $5.557 \times 10^{-5}$ \\
9 & $\mathrm{RP24}$ & $6.4778 \times 10^{-5}$ & $3.7065 \times 10^{-5}$ & $4.9 \times 10^{-5}$ \\
10 & $\mathrm{RP31}$ & $4.1927 \times 10^{-5}$ & $3.5042 \times 10^{-5}$ & $3.833 \times 10^{-5}$ \\
11 & $\mathrm{RP32}$ & $5.4695 \times 10^{-5}$ & $1.5461 \times 10^{-5}$ & $2.908 \times 10^{-5}$ \\
12 & $\mathrm{RP33}$ & $2.1032 \times 10^{-5}$ & $1.234 \times 10^{-5}$ & $1.611 \times 10^{-5}$ \\
13 & $\mathrm{RP34}$ & $3.9967 \times 10^{-4}$ & $7.296 \times 10^{-6}$ & $5.4 \times 10^{-5}$ \\
14 & $\mathrm{RP35}$ & $1.3215 \times 10^{-5}$ & $6.6503 \times 10^{-6}$ & $9.343 \times 10^{-6}$ \\
15 & $\mathrm{RP36}$ & $3.3989 \times 10^{-2}$ & $2.1879 \times 10^{-6}$ & $2.727 \times 10^{-4}$ \\
\hline
\end{tabular}

\section{Reliability Assessment of Space Station Configuration Mission}

According to above mentioned model and assessment data, the space station configuration mission reliability is assessed and the result is shown in Table 7. The LOM state has the highest state probability, which needs to be analyzed carefully.

Table 7. Configuration mission reliability final states probabilities.

\begin{tabular}{cc}
\hline End State & Mean Probability \\
\hline MS & 0.9912 \\
LOC & 0.002733 \\
LOP & 0.0007357 \\
LOM & 0.005322 \\
\hline
\end{tabular}

According to the fault model of KTV phase, the LOM state is influenced by the three layers and three types of risks. Thus, the risk plan should include platform equipment reliability growth and management process improvement.

\section{Conclusions and Future Works}

This paper takes the space station as the research objective, and proposes a PRPA method to assess the configuration reliability in the early stage. First, the multi-layers and multi-type risks are identified. Through the qualitative risk feature analysis, the key risks are determined, and the high load risks are determined by the quantitative risk feature analysis. Through the ET and FT methods, the assessment model is built, and the high load risks' occurrence probability and propagation probability data are collected from the database. Based on the above work, the configuration reliability is assessed and the weakness of the configuration mission is determined at the same time. Along with the space station configuration process, the PRPA method still needs to be improved in the 
following ways to satisfy the whole configuration assessment request: (1) building more exact risk propagation models to determine propagation paths; (2) building more accurate assessment probability calculation methods to improve assessment accuracy; (3) carrying out deeper reliability assessment result analysis.

Author Contributions: Conceptualization, X.L.; data curation, X.L. and F.L.; methodology, X.L.; formal analysis, X.L.; formal analysis, X.L.; writing—original draft preparation, X.L. All authors have read and agreed to the published version of the manuscript.

Funding: This research was funded by the National Natural Science Foundation of China grant number 51875089.

Institutional Review Board Statement: Not applicable.

Informed Consent Statement: Not applicable.

Data Availability Statement: The data presented in this article are generated during the study.

Conflicts of Interest: The authors declare no conflict of interest.

\section{References}

1. Wang, K.Q.; Zhang, B.N.; Xing, T. Preliminary integrated analysis for modeling and optimizing space stations at conceptual level. Aerosp. Sci. Technol. 2017, 71, 420-431. [CrossRef]

2. Wang, X.H.; Mao, L.H.; Yue, Y.X.; Zhao, J.W. Manned lunar landing mission scale analysis and flight scheme selection based on mission architecture matrix. Acta Astronaut. 2018, 152, 385-395. [CrossRef]

3. Ryan, C.W.; John, D.B.; Damon, F.L.; Austin, K.N. Cargo logistics for a Notional Mars Base using Solar Electric Propulsion. Acta Astronaut. 2019, 156, 51-57. [CrossRef]

4. Antonio, A.; Laura, G. Risk assessment in the aerospace industry. Saf. Sci. 2002, 40, 271-298.

5. Mario, B.; Gwyn, G. A Bayesian approach for predicting risk of autonomous underwater vehicle loss during their missions. Reliab. Eng. Syst. Saf. 2016, 146, 55-67.

6. Li, X.Y.; Huang, H.Z.; Li, Y.F.; Zio, E. Reliability Assessment of Multi-state Phased Mission System with Non-repairable Multi-state Components. Appl. Math. Model. 2018, 61, 181-199. [CrossRef]

7. Li, X.Y.; Huang, H.Z.; Li, Y.F. Reliability analysis of phased mission system with non-exponential and partially repairable components. Reliab. Eng. Syst. Saf. 2018, 175, 119-127. [CrossRef]

8. Li, X.Y.; Li, Y.F.; Huang, H.Z.; Zio, E. Reliability Assessment of Phased-mission Systems Under Random Shocks. Reliab. Eng. Syst. Saf. 2018, 180, 352-361. [CrossRef]

9. Marko, Č. Application of shutdown probabilistic safety assessment. Reliab. Eng. Syst. Saf. 2018, 178, 147-155.

10. Payam, A.H.; Mohammad, R. Probabilistic risk assessment of oil spill from offshore oil wells in Persian Gulf. Mar. Pollut. Bull. 2018, 136, 291-299.

11. Diego, M.; Alper, Y.; Tunc, A.; Kyle, M.; Richard, D. Scenario clustering and dynamic probabilistic risk assessment. Reliab. Eng. Syst. Saf. 2013, 115, 146-160.

12. Ha, B.; Tatsuya, S.; Justin, P.; Seyed, R.; Ernie, K.; Zahra, M. An algorithm for enhancing spatiotemporal resolution of probabilistic risk assessment to address emergent safety concerns in nuclear power plants. Reliab. Eng. Syst. Saf. 2019, 185, 405-428.

13. Donovan, L.M.; Christopher, J.M.; Susie, G. Engineering Risk Assessment of a dynamic space propulsion system benchmark problem. Reliab. Eng. Syst. Saf. 2016, 145, 316-328.

14. Papazoglou, I.A.; Aneziris, O.N.; Bellamy, L.J.; Ale, B.J.M.; Oh, J. Multi-hazard multi-person quantitative occupational risk model and risk management. Reliab. Eng. Syst. Saf. 2017, 167, 310-326. [CrossRef]

15. Abdul, A.; Salim, A.; Faisal, K.; Chris, S.; Annes, L. Operational risk assessment model for marine vessels. Reliab. Eng. Syst. Saf. 2019, 185, 348-361.

16. Terje, A.; Zio, E. Some considerations on the treatment of uncertainties in risk assessment for practical decision making. Reliab. Eng. Syst. Saf. 2011, 96, 64-74.

17. Mi, J.; Li, Y.F.; Yang, Y.J.; Peng, W.; Huang, H.Z. Reliability assessment of complex electromechanical systems under epistemic uncertainty. Reliab. Eng. Syst. Saf. 2016, 152, 1-15. [CrossRef]

18. Mi, J.; Beer, M.; Li, Y.F.; Broggi, M.; Cheng, Y. Reliability and importance analysis of uncertain system with common cause failures based on survival signature. Reliab. Eng. Syst. Saf. 2020, 201, 69-88. [CrossRef]

19. Mi, J.; Li, Y.F.; Peng, W.; Huang, H.Z. Reliability analysis of complex multi-state system with common cause failure based on evidential networks. Reliab. Eng. Syst. Saf. 2018, 174, 71-81. [CrossRef]

20. Mi, J.; Li, Y.F.; Liu, Y.; Yang, Y.J.; Huang, H.Z. Belief universal generating function analysis of multi-state systems under epistemic uncertainty and common cause failures. IEEE Trans. Reliab. 2015, 64, 1300-1309. [CrossRef]

21. Li, Y.F.; Liu, Y.; Huang, T.; Huang, H.Z.; Mi, J. Reliability assessment for systems suffering common cause failure based on Bayesian networks and proportional hazards model. Qual. Reliab. Eng. Int. 2020, 36, 2509-2520. [CrossRef] 
22. Li, Y.F.; Huang, H.Z.; Mi, J.; Peng, W.; Han, X. Reliability analysis of multi-state systems with common cause failures based on Bayesian network and fuzzy probability. Ann. Oper. Res. 2019. [CrossRef]

23. Su, W.; Ren, J. Risk propagation model based on social life and credit activities multilayers fusion network. Concurr. Comput. Pr. Exper. 2019, 31, e4732. [CrossRef]

24. Zhu, F.; Zhong, P.A.; Sun, Y.M.; William, W.G.Y. Real-time optimal flood control decision making and risk propagation under multiple uncertainties. Water Resour. Res. 2017, 53, 10635-10654. [CrossRef]

25. Xu, S.; Wang, P. Identifying important nodes by adaptive LeaderRank. Phys. A Stat. Mech. Its Appl. 2017, 469, 654-664. [CrossRef]

26. Li, Q.; Zhou, T.; Lü, L.Y.; Chen, D.B. Identifying influential spreaders by weighted LeaderRank. Phys. A Stat. Mech. Its Appl. 2014, 404, 47-55. [CrossRef]

27. Surya, K.; Tripti, M.; Vinay, K.J.; Deepak, K.J.; Arun, K.S. LeaderRank based k-means clustering initialization method for collaborative filtering. Comput. Electr. Eng. 2018, 69, 598-609.

28. Groen, F.J.; Smidts, C.S.; Mosleh, A. QRAS-The Quantitative Risk Assessment System. In Proceedings of the 46th Annual Reliability and Maintainability Symposium, Seattle, WA, USA, 28-31 January 2002; pp. 349-355.

29. Durga, R.K.; Vinh, N.D. Quantification of Dynamic Event Trees-A comparison with event trees for MLOCA scenario. Reliab. Eng. Syst. Saf. 2016, 147, 19-31.

30. Raiyan, A.; Das, S.; Islam, M.R. Event Tree Analysis of Marine Accidents in Bangladesh. Procedia Eng. 2017, 194, 276-283. [CrossRef]

31. Xin, S.; Zhang, L.; Jin, X.N.; Zhang, Q. Reconstruction of the fault tree based on accident evolution. Process Saf. Environ. Prot. 2019, 121, 307-311. [CrossRef]

32. Enno, R.; Daniël, R.; Pieter, T.B.; Mariëlle, S. Rare event simulation for dynamic fault trees. Reliab. Eng. Syst. Saf. 2019, 186, 220-231.

33. Gu, W.W.; Luo, J.; Liu, J.F. Exploring small-world network with an elite-clique: Bringing embeddedness theory into the dynamic evolution of a venture capital network. Soc. Netw. 2019, 57, 70-81. [CrossRef]

34. Zhou, Y.; Li, C.S.; Ding, L.Y. Combining association rules mining with complex networks to monitor coupled risks. Reliab. Eng. Syst. Saf. 2019, 186, 194-208. [CrossRef]

35. Wang, H.; Gu, T.; Jin, M.Z.; Zhao, R.; Wang, G.X. The complexity measurement and evolution analysis of supply chain network under disruption risks. Chaos Solitons Fractals 2018, 116, 72-78. [CrossRef]

36. Wang, Z.Y.; David, J.H.; Chen, G.; Dong, Z.Y. Power system cascading risk assessment based on complex network theory. Phys. A Stat. Mech. Its Appl. 2017, 482, 532-543. [CrossRef]

37. Gong, L.; Zhang, S.G.; Tang, P.; Feng, Y. Implication of mishaps to preliminary hazard analysis of hypersonic vehicles. Procedia Eng. 2014, 80, 437-444. [CrossRef]

38. Abdul, A.; Salim, A.; Faisal, I.K. An ontology-based method for hazard identification and causation analysis. Process Saf. Environ. Prot. 2019, 123, 87-98.

39. Jain, P.; Rogers, W.J.; Pasman, H.J.; Keim, K.K.; Mannan, M.S. A Resilience-based Integrated Process Systems Hazard Analysis (RIPSHA) approach: Part I plant system layer. Process Saf. Environ. Prot. 2018, 116, 92-105. [CrossRef]

40. Yu, X.C.; Liang, W.; Zhang, L.B.; Genserik, R.; Lu, L.L. Risk assessment of the maintenance process for onshore oil and gas transmission pipelines under uncertainty. Reliab. Eng. Syst. Saf. 2018, 177, 50-67. [CrossRef]

41. Guo, J.; Li, Z.J.; Thomas, K. A Bayesian approach for integrating multilevel priors and data for aerospace system reliability assessment. Chin. J. Aeronaut. 2018, 31, 41-53. [CrossRef]

42. Vincent, C.; Mathieu, B.; Jean, M.B.; Jérôme, M.; Nicolas, G. Evaluation of failure probability under parameter epistemic uncertainty: Application to aerospace system reliability assessment. Aerosp. Sci. Technol. 2017, 69, 526-537.

43. Tiffaney, M.A. A case based human reliability assessment using HFACS for complex space operations. J. Space Saf. Eng. 2019, $6,53-59$.

44. Alexander, P.K.; Ginestra, B. Beyond the clustering coefficient: A topological analysis of node neighbourhoods in complex networks. Chaos Solitons Fractals X 2019, 1, 100004.

45. Li, Y.S.; Shang, Y.L.; Yang, Y.T. Clustering coefficients of large networks. Inf. Sci. 2017, 382-383, 350-358. [CrossRef]

46. Gao, F.; Le, A.B.; Xi, L.F.; Yin, S.H. Asymptotic formula on average path length of fractal networks modeled on Sierpinski gasket. J. Math. Anal. Appl. 2016, 434, 1581-1596. [CrossRef]

47. Andreas, I.R.; Konstantinos, S.; Constantinos, I.S. Tuning the average path length of complex networks and its influence to the emergent dynamics of the majority-rule model. Math. Comput. Simul. 2015, 109, 186-196.

48. Julio, F.; Miguel, R. On eigenvector-like centralities for temporal networks: Discrete vs. continuous time scales. J. Comput. Appl. Math. 2018, 330, 1041-1051.

49. Phillip, B. Some unique properties of eigenvector centrality. Soc. Netw. 2007, 29, 555-564. 